\title{
Cenas da periferia: \\ auto-representação como luta por reconhecimento
}

\section{Daniela Zanetti}

\section{Resumo}

Produções audiovisuais "de periferia"

possuem cada vez mais espaços para exibição, principalmente em festivais como o Cine Cufa

e Visões Periféricas. Considerando a existência de um discurso pautado pelo direito à auto-

representação, que aglutina e dá sustentação ao chamado "cinema de periferia", este artigo apresenta algumas reflexões acerca do modo como essa produção audiovisual específica articula as representações sociais em torno de sujeitos e territórios periféricos e é usada como instrumento de luta por reconhecimento.

Palavras-chave

Audiovisual. Periferia. Representações.

Reconhecimento.

\section{Daniela Zanetti | daniela.zanetti@gmail.com}

Doutoranda em Comunicação e Cultura Contemporânea pela Universidade Federal da Bahia - UFBA. Bolsista do Conselho Nacional de Pesquisa - CNPq.

\section{Introdução}

0 que poderia haver de comum entre os filmes

Falcão, meninos do tráfico (MV Bill e Celso Athayde/Cufa), O Campim (Clandestino Filmes/ Cinema Nosso), Neguinho e Kika (Nós do Morro), o filme do filme roubado do roubo da loja de filme (Marcelo Yuka, Júlio Pecly e Paulo Silva/Cavídeo Produções) e Rap, o canto da Ceilândia (Adirley Queiroz/Forcine, UnB), fora o fato de terem sido exibidos em festivais que se dedicam a produções audiovisuais "da periferia", especificamente as mostras Visões Periféricas e Cine Cufa? 0 que os caracteriza como produtos que poderiam representar uma "cultura da periferia"?

Com 0 objetivo de identificar a existência e examinar as características de uma produção audiovisual chamada "de periferia" (e o discurso que a sustenta), este artigo desenvolve uma articulação teórica em torno dos conceitos de representação, esfera da visibilidade pública e luta por reconhecimento, de modo a criar as bases de uma metodologia de análise do "cinema de periferia" e de suas instâncias de produção e difusão. Entendendo a linguagem audiovisual 
como plataforma de representações e discursos, o objetivo é investigar como certas práticas audiovisuais existentes em favelas e periferias das grandes cidades brasileiras se configuram em estratégias de auto-representação e são tomadas como instrumento de lutas por reconhecimento social.

\section{Reconhecendo o fenômeno}

Para compreender o que vem sendo chamado neste trabalho de "produção audiovisual de periferia" (ou "cinema de periferia") é preciso inicialmente localizar esse fenômeno, situá-lo dentro de um contexto.

Esse conceito vem se estabelecendo e adquirindo certa projeção publicamente principalmente através da realização de festivais e mostras que se propõem a dar visibilidade à crescente produção audiovisual $^{1}$ desenvolvida em periferias de todo o país, como o Festival

\section{Internacional Cine Cufa (RJ), o Festival Visões}

\section{Periféricas (RJ) e o Cine Periferia Criativa}

(DF), que tiveram suas primeiras edições em 2007. Há outras experiências que também se dedicam ao chamado "cinema de quebrada", ou seja, obras produzidas por cineastas da periferia. Entretanto, por razões metodológicas, optamos por estudar trabalhos exibidos e/ou premiados apenas nos dois referidos festivais cariocas, que também já estão programados para acontecer em 2008.

o Festival Cine Cufa, realizado entre 4 e 16 de setembro no Centro Cultural Banco do Brasil, foi uma iniciativa da Central Única das Favelas do Rio de Janeiro. 0 evento foi criado para exibir filmes produzidos nos cursos de audiovisual da própria Cufa e de outras entidades. Foram exibidas cerca de 50 produções (do Brasil e de outros países, como África do Sul, Angola, Estados Unidos, França, Índia e Inglaterra) que "abordam o cotidiano das favelas e tratam de família, religião, preconceito, exclusão social, violência e o convívio com o tráfico de drogas" (CINECUFA, 2007). 0 folder distribuído no festival traz a seguinte chamada: "0 mundo já retratou a periferia. Agora é a vez das posições se inverterem", e o texto de apresentação diz:

0 Cine Cufa é um festival dedicado às obras audiovisuais produzidas por periferias de todo 0 mundo e traz como proposta o incentivo a uma nova ordem cultural e artística, que tem como objetivo maior mostrar um novo ponto de vista: a capacidade de contribuir não somente com personagens que possam atuar à frente das câmeras, mas também como protagonistas atrás delas. [...] Temos como objetivo fomentar a construção de uma identidade que passe a atuar mais fortemente no mercado cinematográfico, fazendo com que os realizadores dessa

0 audiovisual é um termo "guarda-chuva" que abarca formatos, estilos e suportes distintos, incluindo todo 0 tipo produção que combine imagem e som (linguagem verbal, efeitos sonoros, música, etc.). Pode ter como meio de circulação o cinema, a televisão, o vídeo analógico ou digital, ou mesmo a internet e, mais recentemente, aparelhos celulares. A denominação pode abranger curtas, médias ou longas-metragens, nos gêneros ficção, artístico (vídeo-arte) ou documentário, além de programas jornalísticos, ficções televisivas, videoclipes, etc. No campo do "cinema de periferia", predominam produções mais baratas, feitas com poucos recursos e muitas vezes utilizando câmeras portáteis. 
crescente vertente audiovisual reconheçam-se como representantes de um novo e legítimo movimento estético, social e político. (CINECUFA, 2007)

\section{0 festival Visões Periféricas, organizado pelo}

Observatório de Favelas, aconteceu de 6 a 16 de junho, no Centro Cultural da Caixa Econômica Federal, no Centro do Rio de Janeiro, e em outros espaços da região metropolitana. Foram 184 trabalhos inscritos e 34 selecionados para a mostra competitiva, entre vídeos produzidos por "escolas populares de comunicação e audiovisual, e coletivos de realizadores, do país". As obras concorriam aos prêmios de Melhor Filme, Crítica Social, Retrato da Periferia e Coisas Nossas. No catálogo deste festival, lê-se uma provocação: "Como a periferia vê o mundo? Como a periferia vê a periferia? E, afinal, de que periferia estamos falando?". 0 texto ainda ressalta: "É comum que as representações dos espaços populares sejam marcadas pelo estereótipo da pobreza e da violência ou por um tom folclórico". 0 texto de apresentação do festival defende que o cotidiano da periferia não é tematizado, mas sim transformado em espetáculo, e que, frente a essa realidade, 0 evento parte da acepção de que a cultura é um importante instrumento "para a construção de um novo olhar sobre as periferias brasileiras" (VISÕES PERIFÉRICAS, 2007, p. 5).

Além das exibições, os dois eventos realizaram debates sobre temas que se tornaram recorrentes nesse circuito: a relação entre "centro" e "periferia", novas possibilidades de produção cinematográfica, formação de platéias, mercado de distribuição das produções da "periferia", políticas de audiovisual, ampliação de editais públicos, modos de representação da periferia na mídia, etc. Há um discurso que demarca a existência de um tipo específico de produção ("audiovisual popular", "núcleos populares de formação audiovisual", "produções periféricas"), a necessidade de ampliação de modos de difusão e de espaços alternativos de exibição, a importância da diversidade sócio-cultural nas produções, além, claro, de reivindicações "políticas", que visam a ampliação da participação da periferia no mercado do audiovisual como um todo.

Referências à utilização do audiovisual e à importância dada às representações decorrentes desses trabalhos também podem ser encontradas nos sites das instituições e núcleos de produção audiovisual "da periferia", como 0 Cine Cufa Audiovisual (www.cufaaudiovisual. blogspot.com), um núcleo que reúne diretores, produtores e roteiristas, muitos dos quais formados pela própria instituição. Com patrocínio da Fundação Ford, a ONG mantém ainda um curso de audiovisual, voltado para a transformação e ampliação das perspectivas profissionais e pessoais, já que além de promover a inserção no mercado de trabalho, contribui de forma determinante na elevação da auto-estima dos jovens. 0 site do projeto 
ressalta ainda que, visando a inclusão de jovens de camadas menos favorecidas da sociedade, 0 curso pretende formar alunos multiplicadores de conhecimento, mais conscientes de sua imagem e das formas possíveis de retratá-la.

Esse conjunto de fragmentos discursivos ressalta uma preocupação (por parte dos atores sociais envolvidos nesse trabalho de produção e exibição de obras audiovisuais) acerca da importância das representações de periferia, do poder da imagem e da lógica da mídia no tocante às disputas por reconhecimento $\mathrm{e}$ legitimidade na esfera pública. Há ainda uma forte referência à idéia de pertencimento (a uma ideologia, a um lugar, a um coletivo, etc.) associada à representação da periferia.

Essas evidências, de certa forma, ajudam a caracterizar o fenômeno do "audiovisual de periferia", marcado pelo estabelecimento de um debate das chamadas periferias (mundiais e locais) em torno de suas próprias realidades, debate que é cada vez mais pautado pela necessidade de uma visibilidade pública. Daí a necessidade de instrumentos para se (re)pensar e (re)elaborar suas próprias representações. Pode-se considerar, então, que há um discurso "organizado" que envolve e "subscreve" um determinado conjunto de representações inscritas numa produção audiovisual chamada "de periferia", ou "periférica".

\section{Periferia, uma categoria midiática}

Um aspecto em particular normalmente se mostra como um complicador no que se refere à definição e à classificação de um tipo de cinema exclusivo da periferia, um produto audiovisual periférico: o próprio conceito de periferia. É possível existir um "cinema de periferia"? 0 que 0 torna diferente de outras produções audiovisuais?

No que concerne ao campo das Ciências Sociais e da Comunicação, o conceito de "periferia urbana" deve ser entendido de maneira mais ampla, pois não se restringe a uma dimensão geográfica e social, incorporando uma dimensão simbólica (imaginário, representações sociais, discursos, etc.). Para além das condições reais de existência (associadas às dimensões econômica, social e cultural), nota-se que há também um aspecto fundamental em jogo na compreensão de territórios periféricos: 0 tipo de representação construída em torno destes, e 0 modo como são representados na esfera pública, principalmente por meio da mídia. São, portanto, as representações construídas em torno do conceito de periferia - dentro e fora da mídia - que mais interessam para se compreender o fenômeno social no qual está inserida essa produção audiovisual específica. Se a periferia se tornou uma categoria cultural, um gênero, um estereótipo, uma marca ou mesmo uma "grife", isso em muito se deve às representações que 
emergem dos processos de mediação existentes na esfera pública e os discursos atrelados a essas representações, especificamente aquelas difundidas pelos meios de comunicação de grande alcance de público.

A partir dos anos 90, diversas realizações televisivas e cinematográficas "desencadearam uma sucessão de proposições que reelaboraram o lugar das periferias e favelas no universo virtual do que é visível, lócus privilegiado da sociedade contemporânea" (HAMBURGER, 2007). Concentrando-se apenas no âmbito da televisão brasileira, diversos produtos exibidos recentemente investiram em temas de alguma forma relacionados ao universo da periferia e da favela. A telenovela Vidas Opostas (Record) incorporou na trama o universo do tráfico de drogas numa favela, enquanto Duas Caras (Globo) retratou o cotidiano de um grupo de moradores da "comunidade" da Portelinha.

Outras experiências optaram por uma abordagem marcadamente diferenciada sobre a periferia ao investir num discurso positivo, associado às idéias de diversidade cultural, espírito comunitário, criatividade, solidariedade, etc., em oposição à violência, desigualdade, criminalidade, exclusão, etc. (embora estes aspectos possam estar presentes). A série Cidades dos Homens, veiculada pela Rede Globo, produzida em parceria com a 02 Filmes (e que em 2007 deu origem ao filme homônimo de Paulo Morelli); 0 quadro Minha Periferia, apresentado por Regina
Casé e exibido no Fantástico; e a série Antônia, também exibida na Rede Globo, são algumas das produções que circulam comercialmente e que, de certa forma, problematizam a questão da periferia brasileira ao tentar construir novos modos de representação de pessoas e espaços periféricos, além de trazer inovações estéticas e investir em no que se refere à linguagem televisual (KORNIS, 2006; 2007).

Há, contudo, outros processos de mediação que cada vez mais ocorrem de forma periférica, a partir de um conjunto significativo de produtos culturais (especificamente no campo da arte e da comunicação), como vídeos, filmes, fotografias, jornais, emissoras de rádio, agências de noticias, sites, blogs, etc., que falam sobre as periferias urbanas e que são feitos pelos próprios moradores desses "territórios de periferia", principalmente aqueles situados em regiões metropolitanas.

A Rádio Favela (http://www.radiofavelafm. cjb.net/1/), o site do Observatório de Favelas (www.observatoriodefavelas.org.br), o grupo Nós do Morro (www.nosdomorro.com.br), o projeto Imagens do Povo (www.imagensdopovo. blogspot.com) e o documentário Falcão, Meninos do Tráfico (2006), produzido pela Central Única das Favelas (Cufa), são alguns exemplos bem-sucedidos. Hoje muitos espaços considerados de periferia já dispõem de seus próprios canais de comunicação, e os festivais de cinema e vídeo também se enquadram nesse tipo de experiência. 


\section{Comunicação e participação política: luta por auto-representação e reconhecimento}

Representações exprimem a relação de um sujeito com um objeto, envolvendo uma atividade de construção e de simbolização. No que se refere às representações sociais, essa relação acontece a partir de processos decorrentes das práticas sociais, o que inclui os discursos, a arte, os rituais, as mediações, etc.

A produção simbólica, como parte desse universo, é constituída a partir da realidade social. As representações sociais não surgem de sujeitos individuais, mas "nos fenômenos produzidos pelas construções particulares da realidade social" (JOVCHELOVITCH, 1994), originando-se de uma articulação coletiva, de um espaço comum. Como produto das interações e dos fenômenos de comunicação no interior de um grupo social, as representações funcionam como elemento de organização das relações simbólicas entre atores sociais. (JOVCHELOVITCH, 1994; VALA; MONTEIRO, 2004) Nesse sentido, as representações são formadas tanto nos espaços públicos, através dos sentidos construídos coletivamente, quanto nas mediações da vida pública, que hoje se configura basicamente através dos meios de comunicação. As representações sociais são 0 suporte básico dos atos comunicativos e sua produção passa pelo processo de mediação social. Quando os indivíduos se questionam sobre fenômenos sociais, acionam as teorias que coletivamente construíram sobre esses mesmos fenômenos, e é com base nessas teorias que buscam e estruturam suas explicações. (VALA; MONTEIRO, 2004; JOVCHELOVITCH, 1994). "Os indivíduos constroem representações sobre a própria estrutura social e as clivagens sociais, e é no quadro das categorias oferecidas por essas representações que se auto-posicionam e desenvolvem redes de relações" (VALA; MONTEIR0, 2004, p. 495).

Tais redes de relações constituem uma das bases necessárias para que os indivíduos possam se reconhecer a partir da alteridade, do "outro", com o qual compartilha representações sociais.

Estas, ao se constituírem em instâncias de institucionalização simbólica, de "enquadramento" dos sentidos, são suportes para a compreensão da realidade, como forma até de criar um sentimento de familiaridade no contexto da vida social. As estruturas de comunicação, ao se constituírem como instâncias de mediação, também são responsáveis pela geração de representações sociais, fenômenos simbólicos produzidos na esfera pública (JOVCHELOVITCH, 2000).

É na esfera pública que se processa 0 debate público, ou seja, "a contraposição argumentativa, a disputa de interesses mediada pela linguagem, as interações lingüísticas competitivas sobre as matérias de interesse político coletivo" (GOMES, 2003, p. 58). Argumentar é ativar e discutir representações sociais. Os atos de comunicação, portanto, nem sempre significam 
partilha de consensos; são, muitas vezes, atos de debate, de discussão e argumentação no interior dos grupos ou entre grupos, no interior das redes de relações. A instância midiática, funcionando como substituto dos espaços comuns coletivos, potencializa a formação dessas redes e mantém constante a circulação e re-significação das representações. A visibilidade pública através da mídia, portanto, tem sido cada vez mais almejada por determinados setores da sociedade civil, como forma de garantir que seus interesses possam fazer parte do debate público. Contudo, essa esfera da visibilidade pública, em grande parte, é controlada pelas indústrias da informação, do entretenimento e da cultura (GOMES, 2003), razões pelas quais têm surgido espaços alternativos de produção e difusão de mensagens (como os festivais de vídeo e cinema citados, por exemplo). Organizações civis, em suas mais variadas formas, tentam justamente ampliar as "frestas" em busca não somente de acesso a canais diversificados de informação e comunicação para serem "consumidos", mas principalmente para serem utilizados por uma maior variedade de atores sociais, no sentido de contribuir para uma maior diversidade de discursos e representações.

Esse confronto discursivo na esfera da visibilidade pública pressupõe também um embate de representações. Atualmente, diferentes nichos de produção discursiva emergem, em parte, de movimentos sociais e outras formas de organização coletiva fundamentadas numa idéia de "emancipação" por meio de práticas simbólicas que envolvem a difusão e a partilha de representações (por vezes comuns a um mesmo grupo, por vezes conflitantes entre si) na esfera da visibilidade pública.

Numa perspectiva mais ampla, pode-se compreender essa articulação de determinados segmentos da sociedade civil em torno do audiovisual como uma forma de participação política dos cidadãos - significando uma forma de exercício da cidadania, ideal da modernidade associado aos conceitos de liberdade de expressão, igualdade de direitos, etc. Cidadania, nesse sentido, diz respeito a uma ampliação de vários tipos de "direitos de usos e acessos", como educação, saúde, trabalho, participação política, moradia, etc. A partir das novas demandas que surgem no contexto das sociedades contemporâneas, cada vez mais amplo se torna 0 espectro de abrangência do exercício da cidadania. E a comunicação tem sido um dos aspectos da cidadania incluídos nessa demanda, principalmente porque se caracteriza como meio, instrumento, e, ao mesmo tempo, como campo de atuação permanente na busca pelo que se convencionou chamar de "inclusões". Pelo menos no cenário brasileiro, podemos destacar como importantes "bandeiras" reivindicatórias a democratização da comunicação e a inclusão digital. Desse modo, a participação política hoje também é marcada - e principalmente - pela busca de uma inserção em diferentes espaços midiáticos. A visibilidade na esfera pública 
proporcionada pelos meios de comunicação se tornou uma meta para se efetivar o debate público e as mobilizações sociais.

Ocorre que esse jogo de representações e essa busca pela visibilidade cada vez mais são perpassados pela linguagem audiovisual e suas especificidades estéticas e narrativas. Como já ressaltado, um aspecto evidenciado nos discursos que acompanham a produção audiovisual de periferia - através de folders, catálogos, sites, blogs, listas de discussão, etc. - é o direito à "autorepresentação", a possibilidade de indivíduos e coletivos da periferia de exercer maior controle sobre suas próprias representações, de modo a refutar aquelas consideradas "erradas" ou nãosatisfatórias, como os estereótipos (geralmente negativos) e as distorções.

Como afirmam Shohat e Stam (2006), a questão crucial em torno dos estereótipos e das distorções diz respeito ao fato de que grupos historicamente marginalizados normalmente não têm controle sobre sua própria representação. Se esse outro "periférico" não pode se auto-representar - e falar em nome de si mesmo - restam somente as representações construídas em torno deles pelos "outros", e difundidas pelos meios de comunicação de um modo geral.

Uma dimensão dessa "luta por autorepresentação" surge a partir de alguns vídeos produzidos sob a forma do discurso da valorização dos espaços da periferia, da favela, do morro. Tal valorização emerge da fala de certos personagens ("reais" ou ficcionais) que, como moradores (ou freqüentadores) de territórios periféricos, valorizam suas raízes, seus vínculos afetivos com o lugar, as atividades do cotidiano de trabalho e de lazer, etc. Há um discurso que busca tornar legítimo o fato de se viver na periferia, algo que geralmente é visto como um problema, às vezes como uma "tragédia" urbana da contemporaneidade. Essa visão acerca dos territórios periféricos seria, então, fruto de representações distorcidas e já calcificadas, e muitas vezes geradoras de estereótipos negativos. Como já citado, essa questão está presente no discurso dos festivais Visões Periféricas e Cine Cufa, que são apresentados como espaços de veiculação de discursos outros, formas distintas (e legítimas) de representação da periferia.

A luta por auto-representação vem acompanhada por uma busca de visibilidade pública, o que implica no uso de estratégias de "contraposição argumentativa" a fim de defender interesses coletivos. Nesse sentido, também pode ser compreendida como parte de uma luta por reconhecimento social (HONNETH, 2003; SOUZA, 2003). A apropriação dos meios e linguagens audiovisuais reforça um discurso de "inclusão" e de "acesso" igualitário, representando não apenas o poder de dispor dos meios da força simbólica, mas também do "clima", quase sempre hermético, das atenções públicas. Segundo Honneth:

Quanto mais os movimentos sociais conseguem chamar a atenção da esfera pública para a importância negligenciada das propriedades e das 
capacidades representadas por eles de modo coletivo, tanto mais existe para eles a possibilidade de elevar na sociedade o valor social ou, mais precisamente, a reputação de seus membros (HONNETH, 2003, p. 207-208).

Essa reputação está associada à idéia de estima social, proveniente de uma forma de reconhecimento que pressupõe a valorização, de forma igualitária, das capacidades e propriedades dos indivíduos no interior de uma comunidade de valores.

\section{0 audiovisual como plataforma de representações}

Independente do dispositivo - o conjunto de dados, materiais e organizacionais, que inclui os meios e técnicas de produção das imagens, seu modo de circulação e de reprodução, os meios e os suportes de difusão (AUMONT, 1993) -, a obra audiovisual se caracteriza por ser um meio de expressão, vinculado a um tipo específico de organização simbólica. Considerando as especificidades dos vários dispositivos existentes, o importante é atentar para as representações em jogo, o que está "no lugar" da realidade representada - e problematizada.

Numa obra audiovisual, qualquer que seja sua proposta ou gênero, a sociedade não é propriamente mostrada, mas sim representada. Uma obra audiovisual é, antes de tudo, fonte de representações (GOMES, 2004b). Constitui um tipo de encenação que não passa apenas pela atuação dos personagens ou pela composição dos cenários (a construção do espaço diegético), mas também pelo tipo de composição cinematográfica (tipos de enquadramento, de montagem, etc.). "0 filme opera escolhas, organiza elementos entre si, decupa no real e no imaginário, constrói um mundo possível que mantém relações complexas com o mundo real: pode ser em parte seu reflexo, mas também pode ser sua recusa" (VANOYE; GOLIOT-LÉTÉ, 1994, p. 56).

Um filme constitui um ponto de vista sobre o mundo e estrutura a representação da sociedade em espetáculo, em drama (ficcional ou documental). Uma obra audiovisual é uma composição de dispositivos e estratégias e reúne diversos elementos articulados de forma a produzir determinados efeitos sobre um apreciador. 0 criador de uma obra audiovisual é num "compositor de representações", e sua função é projetar, prever e organizar estrategicamente aqueles efeitos que se realizam no momento da apreciação. 0 criador, de alguma forma, terá que construir a recepção de sua obra. (GOMES, 2004b).

A adoção de determinadas estratégias, contudo, pode garantir certos efeitos junto ao espectador e articular um discurso específico, mas até que ponto consegue "controlar" de fato as representações sociais em jogo? E como essas representações são acionadas na instância fílmica?

Tomemos como exemplo a análise de duas produções "de periferia": Rap, o canto $d a$ Ceilândia e O filme do filme roubado do roubo 
da loja de filme, exibidos nos festivais Visões

Periféricas e Cine Cufa de 2007.

No caso de Rap, o canto da Ceilândia (2005, 15

min), a ênfase é dada aos depoimentos, às falas

de seus entrevistados, e os recursos audiovisuais

utilizados são mais clássicos e formais. A

análise, então, deve privilegiar o discurso dos

protagonistas. 0 vídeo é um documentário sobre

o movimento hip hop numa cidade-satélite de

Brasília, Ceilândia, a partir do ponto de vista

de quatro rappers da região: Marquim (Tropa

de Elite), X (Câmbio Negro), Japão (Viela 17)

e DJ Jamaika (Antídoto). 0 filme tem direção e

roteiro de Adirley Queiroz, formado em cinema

pela Universidade de Brasília e morador da

Ceilândia. 0 curta foi premiado em diversos

festivais entre 2005 e 2006 e recebeu os prêmios

de Melhor Curta do Júri Oficial e de Melhor

Curta do Júri Popular no Festival de Brasília de

2005. 0 fio condutor do documentário está nos

depoimentos dos rappers, que falam sobre 0

movimento hip hop e a relação de suas trajetórias

artísticas com a vida na periferia de Brasília. 0

filme basicamente intercala as entrevistas com

imagens da cidade, fotos de arquivo e imagens dos

artistas se apresentando em shows ou cantando

em estúdio. As próprias casas dos entrevistados

servem de cenário, especialmente a sala de estar.

DJ Jamaika, por exemplo, fala ao lado de um computador na estante, enquanto $\mathrm{X}$ exibe, na

TV de sua sala, um vídeo de seu show. Japão, por outro lado, dá seu depoimento num bar, entre mesas de sinuca. Desse modo, é enfatizado o estilo de vida simples dos artistas entrevistados

(porém com acesso à TV e ao computador), bem como a integração deles com a comunidade da qual fazem parte.

Tecnicamente, trata-se de um documentário "tradicional", tanto na captação das imagens como na montagem, seguindo um formato próximo ao da reportagem. Considerando as categorias sugeridas por Nichols (1991), na obra prevalece o modo expositivo, por conta dos recursos formais utilizados. As falas são dirigidas ao espectador, mesmo que o interlocutor imediato seja 0 diretor. As imagens de arquivo funcionam como ilustração e os depoimentos ajudam a compor um texto homogêneo, mantendo uma continuidade retórica e enfatizando a impressão de objetividade (o que também é sustentado pelas imagens "cruas" da realidade da periferia usadas no documentário). Evidencia-se também um tipo de representação bastante difundido acerca dos rappers de periferia, em sintonia com um discurso predominante do movimento hip hop que destaca 0 artista "da quebrada". As cenas são compostas, em sua maioria, por planos médios e de conjunto, com câmera fixa, iluminação simples e direta e sem efeitos visuais mais elaborados. Na edição, as entrevistas são articuladas com imagens de moradores, casas, ruas e comércios da região.

Por outro lado, há obras marcadas por exercícios estéticos e narrativos, que devem se sobressair na investigação analítica. Um exemplo é o curta- 
metragem de ficção O filme do filme roubado do roubo da loja de filme (2007, $7 \mathrm{~min})$, da produtora Cavídeo (RJ), e dirigido por Marcelo Yuka $^{3}$, Júlio Pecly e Paulo Silva. A história narra o momento do assalto a uma locadora de vídeo de um bairro da zona sul carioca. 0 filme dura basicamente 0 tempo do assalto. Contudo, 0 que poderia se configurar num momento de tensão, transforma-se numa situação patética, devido ao tom de ironia presente na relação estabelecida entre os assaltantes e suas vítimas. Inicialmente, vemos pessoas entrando e saindo da locadora. As imagens são estáticas, em preto e branco, e mostram um plano geral de toda a loja, porque teoricamente são feitas pelas câmeras de vigilância interna. Logo em seguida, dois assaltantes entram armados no estabelecimento, onde estão apenas um casal, 0 atendente da locadora e um rapaz. Num determinado momento, um dos assaltantes percebe que 0 homem com a moça é 0 ator Leandro Firmino da Hora, que ficou famoso ao representar o personagem Zé Pequeno no filme Cidade de Deus (2002). Firmino é um dos profissionais egressos das oficinas de atores da Ong Nós do Cinema, que também formou a maioria do elenco de Cidade de Deus. ${ }^{4}$ "Esse não é aquele cara que fez aquele filme, Cidade de Deus, o Zé Pequeno?", pergunta um dos bandidos, que exige que o rapaz do canto da loja ligue a câmera de seu aparelho celular e filme tudo. A partir daí, a imagem torna-se colorida e mais instável, por vezes tremida. 0 tempo todo o rapaz é orientado pelos bandidos como filmar e 0 que filmar. É pela câmera do celular que 0 espectador acompanha 0 desenrolar da situação. Os bandidos então exigem que Firmino (que faz o papel dele mesmo) repita a frase mais famosa de seu personagem em Cidade de Deus: "Dadinho o c...! Meu nome agora é Zé Pequeno, p...!". Em seguida, descobrem também que a moça que 0 acompanha é a atriz Natalia Laje. Eles estranham o fato de um negro estar saindo com uma moça branca e exigem que ela dê um beijo na boca de um dos assaltantes. A provocação não é gratuita, colocando em questão o tema do preconceito racial e também social. Por fim, a dupla de bandidos recolhe os "pertences" das vítimas e foge levando também o celular que registrou todo o evento, e que funcionará como prova de que eles conseguiram assaltar duas "celebridades". Em comum, as duas produções citadas abordam, a partir de diferentes estratégias, questões como a violência (inclusive a simbólica) e a criminalidade, temas que, no entanto, não são centrais e nem aparecem de forma isolada.

Em Rap o canto da Ceilândia, a ênfase no histórico de violência e discriminação existentes

3 Marcelo Yuka, ex-baterista e compositor do grupo 0 Rappa, ficou paraplégico após ter sido baleado num assalto, em 2000. Depois disso, ainda criou o grupo F.Ur.T.O. (Frente Urbana de Trabalhos Organizados) e realiza outros trabalhos na área cultural e social.

Leandro Firmino participou, também, da primeira temporada da série "Cidade dos Homens" e "Palace II", produzidas pela 02 Filmes e exibidas pela Rede Globo. Atuou ainda na novela Vidas Opostas, da Record, além de outros trabalhos no cinema, na televisão e no teatro. 
em torno do surgimento da cidade aciona representações que intensificam a imagem do pobre e do marginalizado como sendo literalmente "jogados" para as periferias. Há inicialmente um discurso de vitimização, do sujeito oprimido. Por outro lado, essa "opressão", na voz dos rappers, transforma-se em discurso de valorização de um certo ethos, que, no caso dos entrevistados, é perpassado pelo hip hop, um movimento musical e cultural altamente codificado pela linguagem, modo de se vestir, gosto musical, opões de entretenimento e consumo, rede social, instâncias de reconhecimento, enfim, um conjunto de aspectos que contribuem para formar um campo (BOURDIEU, 2006) do movimento hip hop no Brasil. Ser morador de Ceilândia implica em fazer parte de uma comunidade associada às idéias de discriminação e de "falta" (de condições materiais, de estrutura, de benefícios, etc.), mas também de identificação (com um estilo musical, uma tribo, um modo de vida, o próprio espaço periférico, etc.). Há um discurso por igualdade de direitos, "inclusão social", etc., mas também de auto-valorização, de afirmação de uma autoestima coletiva.

Já O filme do filme..., por um lado, se destaca por ser construído com imagens captadas por um celular e uma câmera de vigilância, escolha que interfere nas estratégias formais de composição dos quadros. Por outro lado, explora a imagem simbólica de personagens da vida real, misturando dados da realidade e da ficção (o ator
Leandro Firmino e seu mítico personagem Zé Pequeno). Mesmo sendo um tipo de construção narrativa já conhecida (a do ator que é confundido com seu personagem numa ficção), funciona como uma espécie de desmascaramento da ficção, enfatizado pelo fato de que ambos, ator e personagem, sejam reconhecidos por sua identificação com a favela e a periferia (pelo menos para o público que de alguma forma já conhece a trajetória do ator e assistiu ao filme Cidade de Deus). Nesse sentido, o vídeo joga com as representações sociais existentes em torno do ator de origem pobre, do assaltante, das "celebridades" e do próprio cinema.

\section{$6 \mathrm{Em}$ busca de uma conclusão: das representações ao reconhecimento?}

Como dito anteriormente, os discursos nos quais se apóiam os realizadores dos festivais de cinema de periferia sustentam a idéia de que a possibilidade de realização por parte das periferias já pressupõe um tipo de autorepresentação legítima, autêntica, Essa busca muitas vezes está associada à idéia de "retrato da realidade", possível, muitas vezes, através de uma estética realista (ou hiper-realista) ou naturalista. Alguns recursos formais, técnicos e cenográficos (similares às estratégias usadas no filme Cidade de Deus, por exemplo) já foram apontados como característicos desse modo de construção: montagem dinâmica e ágil, participação de atores não-profissionais egressos das próprias comunidades, ruas e 
casas das periferias e favelas como cenário, etc. (KORNIS, 2006; 2007; HAMBURGER, 2007; NAGIB, 2003; XAVIER, 2006). No âmbito do "cinema de periferia", esta estética também é uma característica marcante dos trabalhos citados inicialmente: Falcão, meninos do tráfico, o Campim, Neguinho e Kika, O filme do filme roubado do roubo da loja de filme, Rap, o canto da Ceilândia, entre outros.

Contudo, uma estética mais ou menos realista depende de uma série de outros fatores. 0 que está em jogo não é a questão de fidelidade a uma verdade ou realidade preexistente, mas a "orquestração de discursos ideológicos e perspectivas coletivas" (SHOHAT; STAM, 2006, p. 265). Além disso, não basta assegurar que filmes sejam elaborados pelos próprios moradores da periferia (ou por grupos subalternos e/ou marginalizados, para usar outras denominações utilizadas) para garantir automaticamente um tipo de representação isenta de estereótipos. Abordar temas normalmente relacionados ao universo das favelas e periferias, como a violência, o tráfico de drogas ou a pobreza, por exemplo, também não necessariamente funciona como garantia de maior fidelidade representativa. É preciso estar atento às formas das representações e às estratégias discursivas que sustentam os pontos de vista em jogo nas obras.

De todo modo, ainda assim a produção audiovisual periférica pode representar um tipo de luta por reconhecimento na medida em que, centrada numa comunidade de valores (traduzida por Honneth na idéia de solidariedade), surge e se desenvolve a partir do empenho das capacidades e propriedades dos indivíduos (e coletivos) na busca por estima social. 0 discurso do direito à auto-representação que sustenta essa rede de produção e exibição da periferia encerra uma dimensão simbólica (a divulgação de um determinado tipo de imagem, de discurso), mas também uma dimensão concreta, pois para que seus produtos existam e possam ser vistos, são necessárias condições materiais mínimas, ou seja, condições econômicas. Desse modo, as "lutas por representação" por meio de produções audiovisuais, por exemplo, ultrapassam a dimensão da "realização artística", adquirindo contornos políticos, num sentido mais amplo desse conceito.

Contudo, o que deve ser colocado à prova numa investigação posterior é a real capacidade do cinema de periferia (seus agentes, instituições, produtos, etc.) de não apenas construir suas próprias instâncias de produção, difusão, legitimação e reconhecimento (o que já é muito, diga-se de passagem), mas também de criar condições para desconstruir a "naturalização da desigualdade" e a lógica da "subcidadania" (SOUZA, 2003) que persiste nas sociedades periféricas como a brasileira. 


\section{Referências bibliográficas}

AUMONT, Jacques. A imagem. Campinas: Papirus, 1993.

BOURDIEU, Pierre. 0 poder simbólico. 9. ed. Rio de Janeiro: Bertrand Brasil, 2006.

CINECUFA, Festival Internacional. Rio de Janeiro, 2007.

GOMES, Wilson. Apontamentos sobre o conceito de esfera pública política. In: MAIA, R.;

CASTR0, M. C. P. S. (orgs.). Mídia, esfera pública e identidades coletivas. Belo Horizonte: UFMG, 2003.

Transformações da política na era da

comunicação de massa. São Paulo: Paulus, 2004a.

La poética del cine y la cuestión del método

en el análisis fílmico. Significação, Curitiba, v.21, n.1, p. $85-106,2004 b$.

HAMBURGER, Esther. Violência e pobreza no cinema brasileiro recente. Novos Estudos Cebrap, São Paulo, n.78, p. 113-128, jul. 2007.

HONNETH, Axel. Luta por reconhecimento: a gramática moral dos conflitos sociais. São Paulo: 34, 2003.

JOVCHELOVITCH, Sandra. Vivendo a vida com os outros: intersubjetividade, espaço público e representações sociais. In: JOVCHELOVITCH, Sandra; GUARESHI, Pedrinho. (orgs). Textos em representações sociais. Petrópolis: Vozes, 1994.

Representações sociais e esfera pública: a construção simbólica dos espaços públicos no Brasil. Petrópolis: Vozes, 2000.

KORNIS, Mônica Almeida. Cidade dos Homens e Falcão - meninos do tráfico: representações televisivas da realidade brasileira em tempos de debate sobre direitos e cidadania. In: GOMES, Ângela de Castro (coord.). Direitos e cidadania: justiça, poder e mídia. Rio de Janeiro: FGV, 2007. p. 215-237.
Aventuras urbanas em Cidade dos Homens: estratégias narrativas de inclusão social em seriados ficcionais. Estudos Históricos, Rio de Janeiro, n. 37, pp. 119-141. jan.-jul. 2006.

MOSCOVICI, Serge. Das representações coletivas às representações sociais: elementos para uma história. In: JODELET, Denise (org). As representações sociais. Tradução: Lilian Ulup. Rio de Janeiro: EdUERJ, 2001.

NAGIB, Lúcia. A língua da bala: realismo e violência em Cidade de Deus. Novos Estudos Cebrap, São Paulo, n. 67, p. 181-191, nov. 2003,.

NICHOLS, Bill. Representing reality: issues and concepts in documentary. Bloomington: Indiana University Press, 1991.

SANCHEZ, Pedro Alexandre. A grife periferia. São Paulo: Carta Capital, São Paulo, n. 418, Nov. 2006. Disponível em: <http://cartacapital.com. br/2006/11/5502>. Acesso em: 10 dez. 2007.

SHOHAT, Ella; STAM, Robert. Crítica da imagem eurocêntrica. São Paulo: Cosac Naify, 2006.

SOUZA, Jessé. A construção social da subcidadania. Belo Horizonte: UFMG; Rio de Janeiro: IUPERJ, 2003.

STAM, Robert. Introdução à teoria do cinema. Campinas: Papirus, 2003.

VALA, Jorge; MONTEIRO, Maria Benedicta. Psicologia Social. Lisboa: Fundação Calouste Gulbenkian, 2004.

VANOYE, Francis; GOLIOT-LETÉ, Anne. Ensaio sobre a análise fílmica. Campinas: Papirus, 1994.

VISÕES PERIFÉRICAS, Festival Audiovisual. Rio de Janeiro, 2007.

XAVIER, Ismail. Corrosão social, pragmatismo e ressentimento. Novos Estudos Cebrap, n.75, jul. 2006, p. $139-155$. 
Periphery scenes: self-representation as struggle for recognition

\section{Escenas de la periferia: auto-representación como lucha por reconocimiento}

\section{Abstract}

Audiovisual productions "from the periphery" have nowadays more space for display, mainly in festivals such as Cine Cufa and Visões Periféricas. Considering the existence of a discourse guided by the right to self-representation, which organize and gives support to the so-called "cinema of the periphery", this article presents some thoughts on how this specific audiovisual production articulates social representations around subjects and peripheral territories and is used as an instrument of struggle for recognition.

\section{Keywords}

Audiovisual. Periphery. Representations. Recognition.

\section{Resumen}

Producciones audiovisuales "de periferia" (de los sectores populares urbanos) cuentan cada vez más con espacios para exhibición, en especial festivales y muestras como Cine Cufa y Visões Periféricas.

Considerando la existencia de un discurso pautado por el derecho a la auto-representación, que reúne y da soporte al llamado "cinema de la periferia", este artículo presenta algunas consideraciones sobre el modo como esta producción audiovisual específica articula las representaciones sociales alrededor de sujetos y territórios periféricos y es utilizado como un instrumento de lucha por reconocimiento.

\section{Palabras clave}

Audiovisual. Periferia. Representaciones. Reconocimiento. 


\section{Expediente}

A revista E-Compós é a publicação científica em formato eletrônico da Associação Nacional dos Programas de Pós-Graduação em Comunicação (Compós). Lançada em 2004, tem como principal finalidade difundir a produção acadêmica de pesquisadores da área de Comunicação, inseridos em instituições do Brasil e do exterior.
E-COMPÓS I www.e-compos.org.br I E-ISSN 1808-2599

Revista da Associação Nacional dos Programas de Pós-Graduação em Comunicação. Brasília, v.11, n.2, maio/ago. 2008

A identificação das edições, a partir de 2008 passa a ser volume anual com três números.

\section{CONSELHO EDITORIAL}

\section{Afonso Albuquerque}

Universidade Federal Fluminense, Brasil

Alberto Carlos Augusto Klein

Universidade Estadual de Londrina, Brasi

Alex Fernando Teixeira Primo

Universidade Federal do Rio Grande do Sul, Brasi

Alfredo Vizeu

Universidade Federal de Pernambuco, Brasil

Ana Carolina Damboriarena Escosteguy

Pontifícia Universidade Católica do Rio Grande do Sul, Brasil

Ana Silvia Lopes Davi Médola

Universidade Estadual Paulista, Brasil

André Luiz Martins Lemos

Universidade Federal da Bahia, Brasil

Ângela Freire Prysthon

Universidade Federal de Pernambuco, Brasil

Antônio Fausto Neto

Universidade do Vale do Rio dos Sinos, Brasil

Antonio Carlos Hohlfeldt

Pontifícia Universidade Católica do Rio Grande do Sul, Brasil

Arlindo Ribeiro Machado

Universidade de São Paulo, Brasil

César Geraldo Guimarães

Universidade Federal de Minas Gerais, Brasi

Cristiane Freitas Gutfreind

Pontifícia Universidade Católica do Rio Grande do Sul, Brasil

Denilson Lopes

Universidade Federal do Rio de Janeiro, Brasil

Eduardo Peñuela Cañizal

Universidade Paulista, Brasil

Erick Felinto de Oliveira

Universidade do Estado do Rio de Janeiro, Brasil

Francisco Menezes Martins

Universidade Tuiuti do Paraná, Brasil

Gelson Santana

Universidade Anhembi/Morumbi, Brasil

Hector Ospina

Universidad de Manizales, Colômbia

leda Tucherman

Universidade Federal do Rio de Janeiro, Brasil

Itania Maria Mota Gomes

Universidade Federal da Bahia, Brasil

Janice Caiafa

Universidade Federal do Rio de Janeiro, Brasil

Jeder Silveira Janotti Junior

Universidade Federal da Bahia, Brasil
John DH Downing

University of Texas at Austin, Estados Unidos

José Luiz Aidar Prado

Pontifícia Universidade Católica de São Paulo, Brasil

José Luiz Warren Jardim Gomes Braga

Universidade do Vale do Rio dos Sinos, Brasi

Juremir Machado da Silva

Pontifícia Universidade Católica do Rio Grande do Sul, Brasil

Lorraine Leu

University of Bristol, Grã-Bretanha

Luiz Claudio Martino

Universidade de Brasília, Brasil

Maria Immacolata Vassallo de Lopes

Universidade de São Paulo, Brasil

Maria Lucia Santaella

Pontifícia Universidade Católica de São Paulo, Brasil

Mauro Pereira Porto

Tulane University, Estados Unidos

Muniz Sodre de Araujo Cabral

Universidade Federal do Rio de Janeiro, Brasil

Nilda Aparecida Jacks

Universidade Federal do Rio Grande do Sul, Brasil

Paulo Roberto Gibaldi Vaz

Universidade Federal do Rio de Janeiro, Brasil

Renato Cordeiro Gomes

Pontifícia Universidade Católica do Rio de Janeiro, Brasil

Ronaldo George Helal

Universidade do Estado do Rio de Janeiro, Brasil

Rosana de Lima Soares

Universidade de São Paulo, Brasil

Rossana Reguillo

Instituto Tecnológico y de Estudios Superiores do Occidente, México

Rousiley Celi Moreira Maia

Universidade Federal de Minas Gerais, Brasil

Sebastião Carlos de Morais Squirra

Universidade Metodista de São Paulo, Brasil

Simone Maria Andrade Pereira de Sá

Universidade Federal Fluminense, Brasil

Suzete Venturelli

Universidade de Brasília, Brasil

Valério Cruz Brittos

Universidade do Vale do Rio dos Sinos, Brasil

Veneza Mayora Ronsini

Universidade Federal de Santa Maria, Brasil

Vera Regina Veiga França

Universidade Federal de Minas Gerais, Brasil

\section{COMISSÃO EDITORIAL}

Ana Gruszynski I Universidade Federal do Rio Grande do Sul, Brasil João Freire Filho I Universidade Federal do Rio de Janeiro, Brasil Rose Melo Rocha I Escola Superior de Propaganda e Marketing, Brasil

\section{CONSULTORES AD HOC}

Aníbal Bragança I Universidade Federal Fluminense, Brasi Gisela Castro I Escola Superior de Propaganda e Marketing, Brasil

Gislene Silva I Universidade Federal de Santa Catarina, Brasil

Maria Helena Weber I Universidade Federal do Rio Grande do Sul, Brasil

Rosana de Lima Soares I Universidade de São Paulo, Brasil

Tania Hoff I Escola Superior de Propaganda e Marketing, Brasil

REVISÃO DE TEXTO E TRADUÇÃo I Everton Cardoso

ASSISTÊNCIA EDITORIAL E EDITORAÇÃO ELETRÔNICA I Raquel Castedo
COMPÓS I www.compos.org.br

Associação Nacional dos Programas de Pós-Graduação em Comunicação

Presidente

Erick Felinto de Oliveira

Universidade do Estado do Rio de Janeiro, Brasil erickfelinto@uol.com.br

Vice-presidente

Ana Silvia Lopes Davi Médola

Universidade Estadual Paulista, Brasil

asilvia@faac.unesp.br

Secretária-Geral

Denize Correa Araújo

Universidade Tuiuti do Paraná, Brasil

denizearaujo@hotmail.com 